Regards sur l'économie allemande

Bulletin économique du CIRAC

$107 \mid 2012$

Varia

\title{
Chômage : l'effet du salaire minimum de référence
}

Isabelle Bourgeois

\section{CpenEdition}

\section{Journals}

Édition électronique

URL : http://journals.openedition.org/rea/4499

DOI : $10.4000 /$ rea.4499

ISBN : 978-2-8218-1424-0

ISSN : 1965-0787

Éditeur

CIRAC

Édition imprimée

Date de publication : 20 décembre 2012

Pagination : 37-38

ISSN : 1156-8992

Référence électronique

Isabelle Bourgeois, "Chômage : l'effet du salaire minimum de référence ", Regards sur l'économie allemande [En ligne], 107 | décembre 2012, mis en ligne le 14 janvier 2013, consulté le 15 septembre 2020. URL : http://journals.openedition.org/rea/4499

Ce document a été généré automatiquement le 15 septembre 2020.

(C) CIRAC 


\title{
Chômage : l'effet du salaire minimum de référence
}

\author{
Isabelle Bourgeois
}

1 L'un des principaux obstacles à la réinsertion des chômeurs dans l'emploi réside dans l'appréciation qu'ont de nombreux demandeurs d'emploi du salaire auquel ils pensent pouvoir prétendre. En moyenne, ce salaire minimum de référence était de 8,17€ nets par heure (soit $12 €$ bruts) en 2010 , ce qui est nettement au-dessus des salaires qui leur sont proposés sur le marché du travail.

2 C'est ce qu'il ressort d'une étude empirique que vient de publier l'Institut der deutschen Wirtschaft (IW Trends, 4/2012). Effectuée sur la base de l'enquête SOEP, elle se concentre sur la question suivante : "Quel devrait être le montant du salaire net pour que vous acceptiez un emploi proposé?". Cette question a été posée à plusieurs reprises (2007-2010) à 1000 personnes, dont une moitié de demandeurs d'emploi, l'autre moitié se composant d'écoliers (secondaire), d'étudiants et d'inactifs.

Evolution 2007-2010 des salaires réels de référence (en $€$, aux prix de 2010

\begin{tabular}{|l|l|l|l|l|l|}
\hline \multicolumn{2}{|l|}{ Salaire horaire } & 2007 & 2008 & 2009 & 2010 \\
\hline net & Ecolier (secondaire)/étudiant & 7,97 & 10,91 & 8,98 & 9,35 \\
\hline & Inactif & 9,46 & 8,43 & 8,66 & 9,02 \\
\hline & Chômeur & 8,00 & 7,45 & 7,75 & 7,47 \\
\hline & Total & $\mathbf{8 , 3 8}$ & $\mathbf{8 , 3 5}$ & $\mathbf{8 , 1 7}$ & $\mathbf{8 , 1 7}$ \\
\hline brut & & & & & \\
\hline & Ecolier (secondaire)/étudiant & 12,18 & 17,29 & 13,98 & 14,42 \\
\hline
\end{tabular}




\begin{tabular}{|l|l|l|l|l|l|}
\hline & Inactif & 12,86 & 11,34 & 11,57 & 12,02 \\
\hline & Chômeur & 11,62 & 10,77 & 11,15 & 10,76 \\
\hline & Total & 12,04 & $\mathbf{1 2 , 1 3}$ & $\mathbf{1 1 , 7 4}$ & $\mathbf{1 1 , 7 5}$ \\
\hline
\end{tabular}

\section{Perception décalée chez les inactifs et les étudiants}

3 Le premier constat qui s'impose est la vision disproportionnée du salaire auquel ils peuvent ou pourraient prétendre qu'ont les inactifs et les jeunes poursuivant des études secondaires ou supérieures. Le premier groupe, qui constitue la réserve latente et qui n'est généralement pas concerné directement par la recherche d'un emploi, n'est pas tributaire d'un revenu issu du travail pour vivre, ce qui explique probablement son décalage. De son côté, le second anticipe très vraisemblablement le niveau de salaire auquel il pourra prétendre une fois sa qualification achevée.

\section{Stabilité du salaire minimum de référence}

4 Le second constat est que, globalement, le montant du salaire de référence est resté stable sur la période étudiée. Une seule exception : les jeunes poursuivant des études secondaires ou supérieures. Leurs prétentions semblent guidées par l'optimisme entretenu par la remarquable stabilité de l'emploi et, tout aussi certainement, la forte demande de main-d'œuvre qualifiée.

\section{Le montant du salaire souhaité s'accroît avec la durée du chômage}

5 Le troisième constat est le montant élevé du salaire minimum de référence avancé par les chômeurs. On aurait pu s'attendre à ce que ce montant baisse après la création en $2005 \mathrm{du}$ régime forfaitaire d'assistance aux chômeurs de longue durée et à leurs proches ( Hartz IV ), relèvent les auteurs de l'étude. En effet, l'objectif de ces aides est d'inciter le bénéficiaire au retour en emploi, et leur versement est donc lié en contrepartie à l'obligation d'accepter tout emploi « convenable » (zumutbar), même si le salaire versé est inférieur à celui perçu antérieurement. Or non seulement ce montant n'a guère varié au fil des ans, non seulement il ne baisse pas avec la durée de la période de chômage, mais il reste aussi nettement supérieur aux salaires pratiqués sur le marché du travail. Ainsi, 35 \% des chômeurs interrogés espèrent un montant supérieur de $20 \%$ au maximum aux salaires proposés ; $52 \%$ d'entre eux placent la barre à plus de $20 \%$ au-dessus. Plus précisément : les personnes au chômage depuis plus d'un an (les droits aux allocations chômage expirent au bout de 12 mois, ensuite le demandeur d'emploi peut sous conditions prétendre à l'assistance chômage «Hartz IV») désireraient un salaire dépassant de $31 \%$ en moyenne le niveau pratiqué sur le marché, et supérieur de $23 \%$ au dernier salaire perçu avant l'entrée en chômage. A l'inverse, les 
chômeurs qui retrouvent rapidement un emploi ont une vision plus réaliste de ce à quoi ils peuvent prétendre.

6 Ce décalage montre que le contexte économique semble n'avoir que très peu d'influence, à l'inverse de la référence au salaire antérieur, de la référence à un emploi à temps plein et, surtout, de la situation du foyer. Car plus le revenu du ménage est élevé, plus le salaire de prétention est lui aussi élevé ; il en va de même de la présence d'un ou plusieurs enfants de moins de 16 ans. Et contrairement à ce qu'on pourrait penser, le montant des prestations de transfert perçues n'a, lui, pas d'influence significative sur le salaire souhaité.

\section{L'activation des chômeurs implique donc une information systématique sur la réalité du marché}

7 L'enseignement qu'en tire cette étude de l'Institut der deutschen Wirtschaft, institut de recherche économique proche des milieux patronaux, est que le débat politique sur la révision des différentes prestations de transfert passe à côté de l'essentiel. La principale trappe à inactivité ne réside en effet pas dans la générosité de l'Etat social allemand, mais bien plutôt dans le manque d'information, croissant avec la durée du chômage, sur les réalités du marché du travail. Ses auteurs préconisent donc un effort accru "d'activation» des chômeurs, particulièrement de longue durée, afin de leur permettre de se faire une idée plus réaliste des possibles. Le meilleur moyen pour y parvenir consiste à leur soumettre à intervalles très réguliers des offres d'emploi et/ou à exiger d'eux une quête plus active encore.

INDEX

Mots-clés : chômage, marché du travail, salaire, salaire minimum, emploi, politique de l'emploi 